\title{
Converses amb Carles Parellada Enrich
}

\author{
Entrevistat per Sandra Gilabert i Isabel Viscarro
}

\author{
Universitat Rovira i Virgili
}

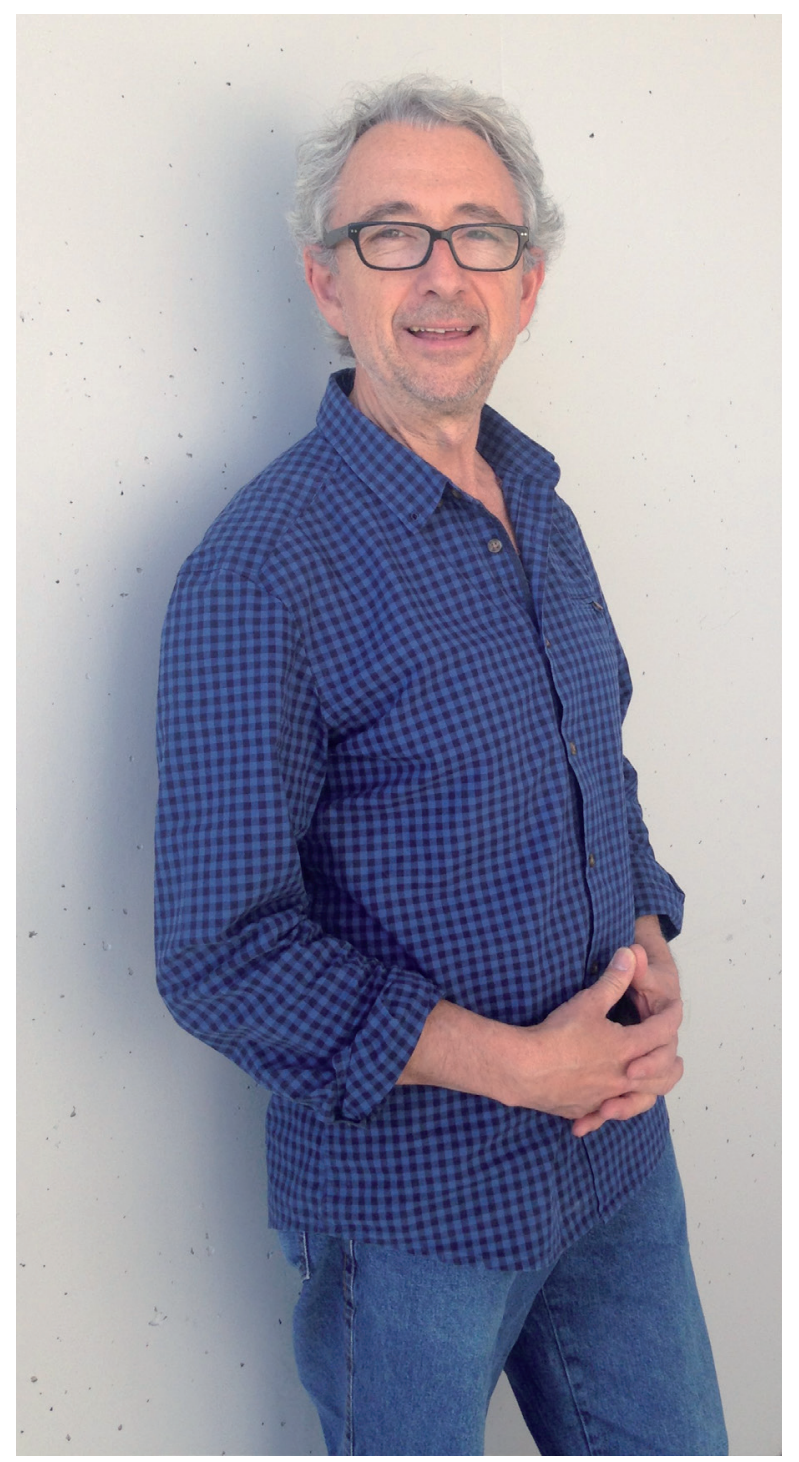

Carles Parellada Enrich és mestre, psicomotricista i terapeuta sistèmic, màster en pedagogia sistèmica per la UDEC de Mèxic i s'ha format en constel-lacions familiars a l'Institut Gestalt de Barcelona. Ha estat col-laborador dels equips de formadors de l'ICE de la Universitat Autònoma de Barcelona i formador en diversos centres de recursos i de professors de Catalunya i de la resta de l'Estat. També és codirector de l'Ārea de Pedagogia Sistèmica de l'Institut Gestalt, codirector del postgrau en Educació Sistèmica de la UAB, codirector del màster en Educació Sistèmica Multidimensional de la URV i docent del mateix màster a la UdG. És assessor de xarxes d'infància i projectes educatius diversos i supervisor d'equips professionals. Juntament amb Mercè Traveset, és cocreador de la Xarxa de Pedagogia Sistèmica de Catalunya i coautor de diversos llibres (els dos darrers La xarxa amorosa per educar i R-Evolució del sistema educatiu, editats per Octaedro) i d'articles publicats en revistes especialitzades en educació.

La formació permanent del professorat i l'assessorament a centres són àmbits en els quals treballa des de fa anys per tot el territori català. A més, participa en múltiples converses amb famílies per tractar temes de l'educació dels fills i de les característiques de les seves etapes evolutives, i supervisa casos d'infants, joves i famílies en situació de risc amb diversos equips professionals (àmbit social, sanitari, judicial...). 


\section{Carles, com vas arribar a la pedagogia sistèmica i què et va motivar d'aquest enfocament?}

No sé si us ha passat alguna vegada: hi ha moments en la vida que succeeixen tantes coses importants alhora que no saps destriar amb exactitud quina va ser abans o quina va venir després. Crec que el gran descobriment, o la certesa que aquesta era una aportació nova al sistema educatiu, em va arribar al I Congrés Internacional de Pedagogia Sistèmica que es va celebrar al CUDEC (Centre Universitari Doctor Emilio Cárdenas, una institució escolar i universitària de Mèxic amb gairebé cinc mil alumnes) l'any 2004, on vaig assistir acompanyant Joan Garriga, director de l'Institut Gestalt de Barcelona, per conèixer Angélica Olvera i suggerir-li que vingués a Barcelona per iniciar una formació en aquesta institució.

Vaig arribar fins aquí de la mà de la formació en constel-lacions familiars que vaig fer al mateix Institut. Anteriorment havia conegut Bertold Ulsamer en la formació que vaig fer en teràpia familiar sistèmica amb el Dr. Sarró, i gràcies a ell vaig conèixer les constel.lacions. Aquests moviments em van fer imaginar que havia d'haver-hi alguna forma de traslladar part de les propostes que vénen d'aquesta mirada de Bert Hellinger a l'escola. També hi van ajudar el llibre de Marianne Franke Eres uno de nosotros, de l'editorial Alma Lepik, a més de les influències, en aquells moments, de científics com Humberto Maturana, Fritjof Capra, Gregg Braden, Edgar Morin...

Si tota la meva vida ha estat una cerca incessant de noves comprensions, i noves aplicacions per a l'educació, la pedagogia sistèmica ha suposat un abans i un després, ja que, ara com ara, sento que aporta, i sintetitza, aspectes clau de la vida de les persones, contextualitzats en l'àmbit educatiu, que també poden veure's reflectits en l'àmbit de la salut $i$ en el del treball social, entre d'altres.

M'ha aportat serenitat, claredat, poder mirar les diferents realitats amb les quals convivim constantment amb una perspectiva més àmplia, més profunda, com si les pogués veure des de l'altre costat. En síntesi, alguna cosa que els que ens movem des d'aquest plantejament expressem com "mirar amb bons ulls", una mirada que no neix en el cap, sinó en el cor, i que genera converses de cor a cor, d’ànima a ànima.
La teva pràctica docent com a mestre psicomotricista es va modificar des de la visió de la pedagogia sistèmica? Consideres que tenen analogies?

Tinc la certesa que la meva perspectiva com a mestre i psicomotricista s'ha vist del tot complementada amb la de la pedagogia sistèmica. Parlo de perspectiva més que de pràctica perquè en el moment en què la vaig descobrir ja no estava a l'escola i a l'aula, sinó treballant a l'ICE de la UAB gestionant i duent a terme activitats de formació permanent. Per tant, la seva influència ha tingut repercussions importants en la meva tasca en l'àmbit de la formació de mestres, en l'acompanyament de les famílies i en la supervisió d’equips professionals que treballen amb infants $\mathrm{i}$ joves en situació de risc.

Hi ha analogies importants, i en destacaria algunes de significatives. Per exemple, que ambdues comporten un canvi de mirada vers els infants i les seves manifestacions vitals, i un canvi de mirada general vers les relacions que s'estableixen en el si de la comunitat educativa. També impliquen una lectura fenomenològica dels esdeveniments que es donen a les aules i a la sala de psicomotricitat, on la intervenció no està tan determinada per la teoria, o la didàctica, sinó més aviat per allò que en cada moment es manifesta en el context de l'activitat. Un tercer element rellevant és el fet que en les formacions d'ambdues perspectives hi ha una part molt important dedicada a la formació personal, element indispensable per a la transformació professional, a més, sens dubte, del valor que es dóna en ambdues al món de les emocions inconscients.

Quants anys fa que estàs connectat professionalment amb l'enfocament sistèmic?

Encara que sembli estrany, fa més de vint anys que hi estic connectat, primer arran de la formació de cinc anys que vaig fer com a terapeuta familiar sistèmic, després amb la formació en constel-lacions familiars, i posteriorment amb la de pedagogia sistèmica, a més dels deu anys posteriors de coordinació i realització de les formacions en pedagogia sistèmica que es fan a Catalunya i arreu de l'Estat, de curta i llarga durada, especialment des de l'Institut Gestalt de Barcelo- 
na, i més recentment des de la UAB a Bellaterra, la URV de Tarragona i la UdG de Girona.

En les introduccions d'algunes formacions sempre poso molt d'èmfasi a explicar que la teoria general de sistemes, que Bertalanffy va explicitar el 1929, porta gairebé cent anys en circulació, que ha tingut i està tenint aplicacions i actualitzacions molt importants en el món de la ciència i en la vida de les persones, però que encara té poca presència en l'àmbit de l’educació. Una part significativa de la meva vida actual està enfocada a potenciar aquesta mirada que no solament és interessant, i oportuna, sinó que és radicalment necessària en un temps en què trontollen moltes coses i es dóna una certa tendència a moure's en la dimensió de la supervivència individual més que al voltant dels avantatges de la cooperació i dels valors de la vida comunitària.

El concepte de pedagogia sistèmica és relativament jove com a proposta pedagògica i cada cop sona amb més força alhora que es va estenent en l'àmbit educatiu i també en el social.
Ens podries explicar, a grans trets, en què consisteix la pedagogia sistèmica?

Com bé diu la mateixa paraula, es tracta d'una combinació especial entre les dimensions de la tradició pedagògica que coneixem, que al nostre país és de llarg recorregut perquè tinc la impressió que hem heretat un llegat extraordinari de l'època de la República, que s'ha anat alimentant i creixent al llarg de les últimes dècades amb les aportacions dels grans pedagogs de diferents indrets del món i dels extraordinaris mestres de la nostra pròpia terra, juntament amb la dimensió de la perspectiva sistèmica, que s'inicia a la fi de la dècada dels anys vint del segle passat, amb aportacions impressionants de científics com Bertalanffy, que continua a meitat d'aquest mateix segle amb les aportacions de la teràpia familiar sistèmica, i que s'actualitza amb les aportacions de les constel-lacions familiars i els ordres de l'amor de Bert Hellinger.

Aquest abordatge sistèmic es fa ressò d'algun dels principis bàsics de la teoria general de sistemes, com el fet que en un sistema, que és una

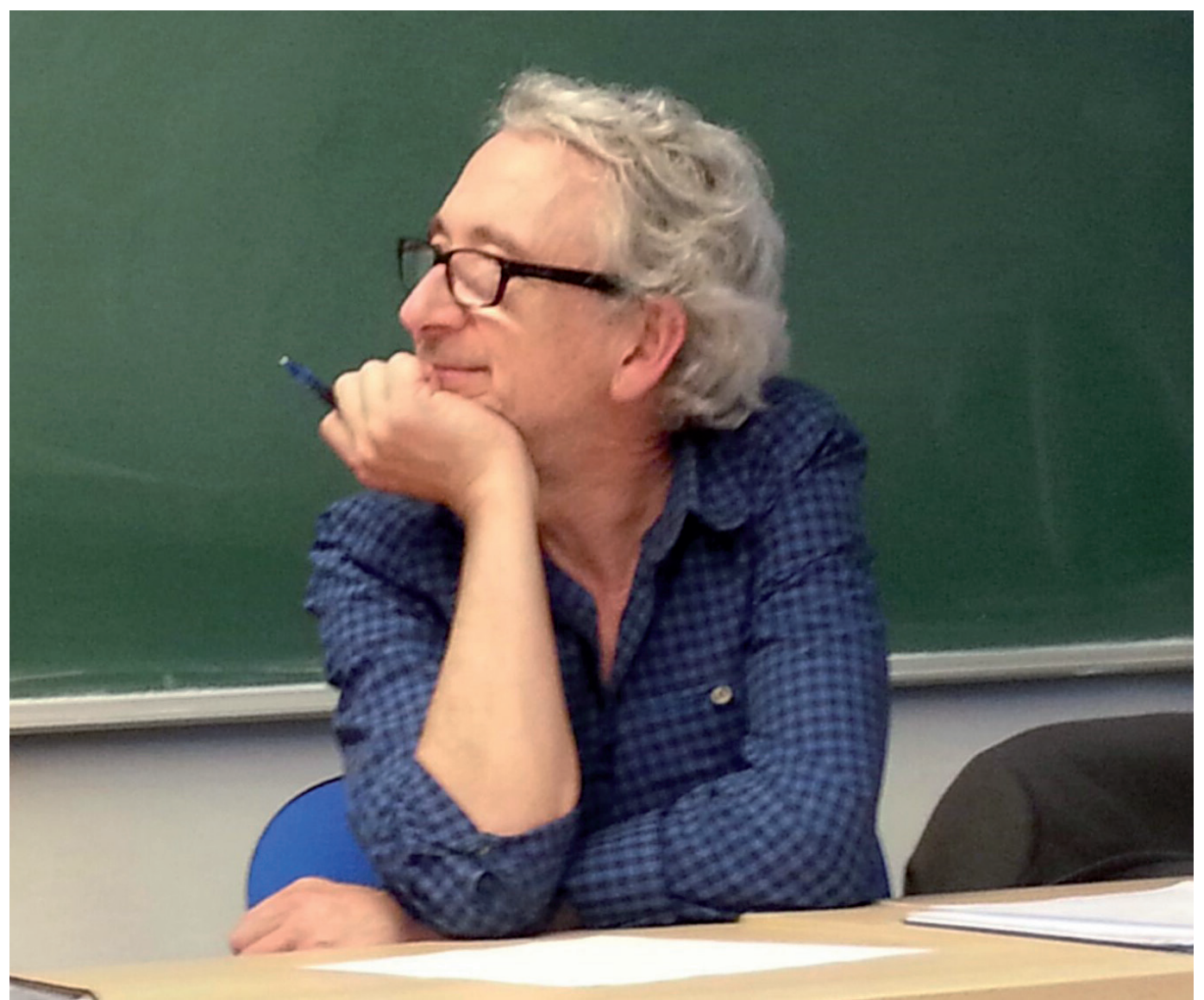


xarxa de relacions, totes les parts estan interconnectades, malgrat que algunes d'aquestes parts no siguin visibles o semblin llunyanes, i, per tant, allò que succeeix en una part de la xarxa afecta tota la xarxa en el seu conjunt. Això ens fa pensar tant en la dinàmica de les famílies com en la dels grups classe o els equips professionals, i fins i tot en les relacions entre les escoles i les mateixes famílies, que són dos subsistemes que es posen en contacte a través de la interacció amb els fills i els alumnes.

Hauríem de dedicar-hi un article en exclusiva, per donar resposta a aquesta pregunta. Per sintetitzar-ho puc dir que és un abordatge pedagògic que té en compte els aspectes relacionals, emocionals i cognitius, conscients i inconscients, per vehicular una millora dels aprenentatges, tant en el camp del coneixement com en el de la relació amb els altres i amb un mateix. En aquest abordatge es dóna molta importància al context, no en va és un plantejament de tipus fenomenològic, i a la vegada s'afina molt en els aspectes dordre tant dels nens i joves com dels adults, buscant contínuament quin és el lloc i la funció que ocupem, de manera que s'enfoca vers un major servei i eficàcia en la tasca que tenim encomanada.

Usem un acrònim per definir en sis paraules on posa l'accent la pedagogia sistèmica: E.S.C.O.L.A. La L comporta el valor del lideratge, que no ha de ser jeràrquic sinó distributiu, en xarxa, i el valor del treball en equip; la $S$ fa referència al significat $i$ la dinàmica dels sistemes (tot el que existeix en l'univers està connectat, una part de la xara retroalimenta la resta); la C, és l'interès que tenim pel context (d'on venim, com és la nostra història...); la $\mathrm{O}$, l'ordre, la ubicació, un ordre de què parlem sovint, sabent que moltes vegades estem desordenats, amb el que això comporta de desajustaments en els diferents espais de relació personal i d'activitat professional; la E són els processos d'ensenyament i aprenentatge, que tant estan evolucionant els últims anys, i la A representa actituds tan importants com la confiança, l'assentiment al destí propi i dels altres, el reconeixement dels altres com a legítims altres (com ens diu Maturana), l'alegria i la gratitud, entre moltes altres de rellevants.
Vivim en un món que cada vegada és més multicultural. Creus que el professorat està preparat per afrontar aquesta realitat de les aules?

Tot i que fa anys que es va iniciar la inclusió de la multiculturalitat als centres educatius, els darrers anys aquesta realitat s'ha incrementat d'una forma ben significativa. És possible que tot i ser un fet arrelat i reconegut encara ens trobem en un procés molt incipient per donar-hi el tractament i la sortida que requereix. El sistema educatiu, i en concret els educadors i educadores, estem cada vegada més conscienciats sobre aquesta realitat $i$, per tant, més preparats per fer-hi front, però encara queden força resistències, ens manca coneixement específic de cadascuna d'aquestes cultures i, sobretot, necessitem desenvolupar unes actituds, i unes pràctiques, més vinculades a les necessitats que se'n deriven.

Afortunadament, la pedagogia sistèmica té uns principis que poden facilitar molt aquesta transformació, ja que contínuament parlem, duem a terme pràctiques vinculades amb la inclusió i la conciliació. A més a més, una de les màximes d'aquesta perspectiva pedagògica i de vida se sustenta a aconseguir que ens puguem mirar amb bons ulls. No es tracta de canviar els altres perquè es facin a semblança nostra, es tracta més aviat de canviar nosaltres perquè tothom senti que pertany i que té un lloc de dignitat, ja sigui a l'aula, als centres educatius o a la societat.

El relativament recent fenomen dels refugiats, degut a la immigració per motius de guerra, està generant, i continuarà generant en els propers anys, reptes de convivència i de consciència molt importants als quals cal donar una resposta ràpida i coherent. Tenim una gran confiança que la mirada sistèmica pot contribuir a trobar fórmules i solucions que permetin apaivagar una mica el dolor i el malestar que aquesta realitat està generant en les comunitats, tant les receptores com aquelles de les quals arriben aquestes persones, aquests ciutadans del món amb tots els seus drets que avui dia són apàtrides perduts en la inoperància dels estats i víctimes d'un sistema social, polític i econòmic que fa aigües per tot arreu.

A tall d'aclariment, parlem de pedagogia sistèmica de la mateixa manera que parlem d'educació sistèmica. Els darrers anys hi hem afegit 


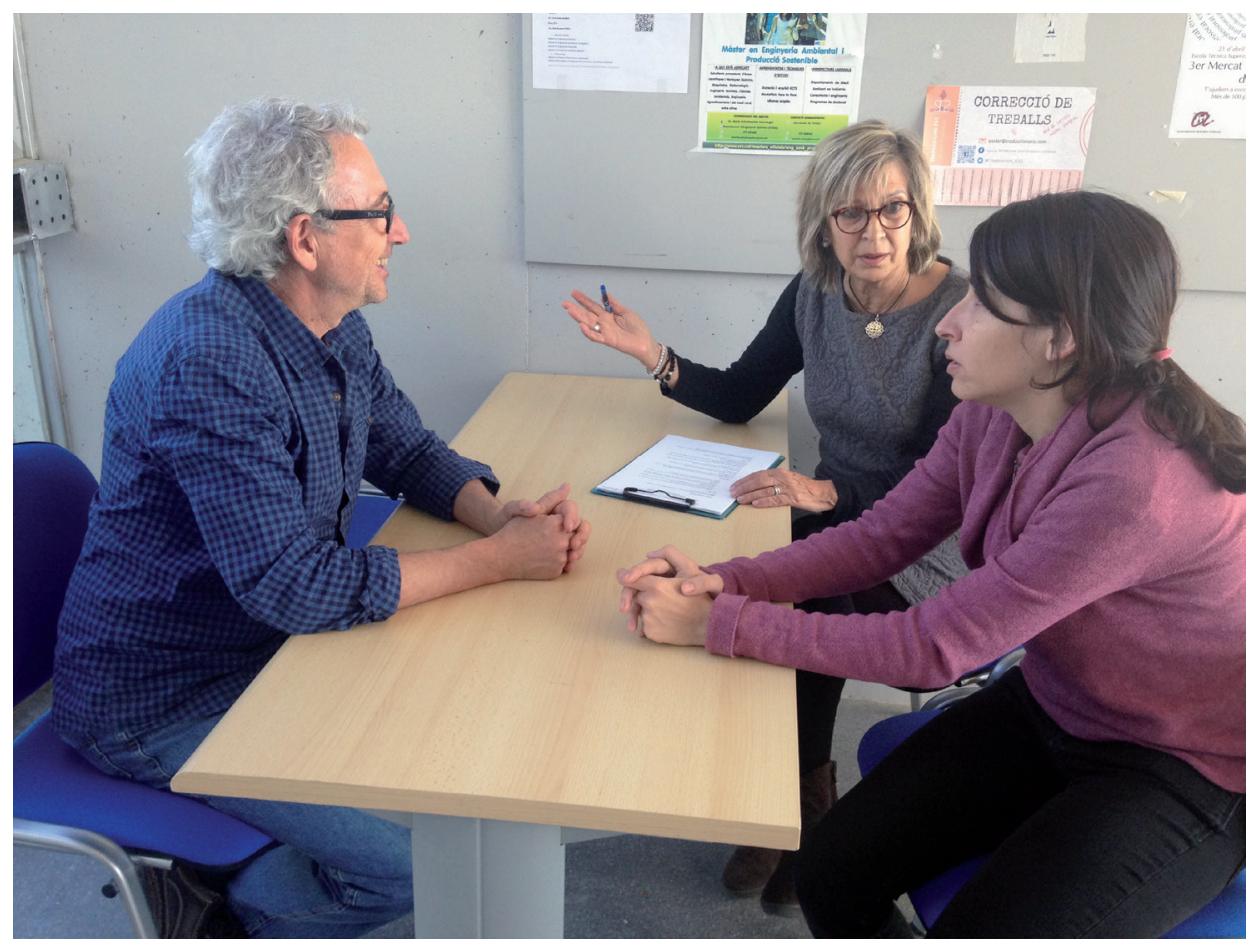

l'adjectiu multidimensional perquè ens hem adonat que és una pedagogia, una educació, que contempla una gran multiplicitat de dimensions (el funcionament dels tres cervells, les diferents generacions, les diferents intel-ligències, la funció de l'observador com a modificador de la realitat, realitat i món simbòlic...).

L'experiència ens demostra que hi ha un nombre considerable de professionals de l'educació que busquen eines, instruments, teories... que els ajudin a millorar la comunicació amb les criatures per poder facilitar l'aprenentatge. Creus que la pedagogia sistèmica pot contribuir d'alguna manera a satisfer les inquietuds d'aquests professionals?

N'estic del tot convençut, i podria estendre'm a bastament en aquesta pregunta, que permetria obrir converses a molts nivells. De tota manera, em centraré en alguns aspectes. El primer és que la pedagogia sistèmica desplega una tasca relacional i emocional des d'una perspectiva molt profunda, ja que a hores d'ara coneixem força bé la complexitat de les dinàmiques relacionals en les famílies, en els equips i en les organitzacions. Tenim respecte, però no por, al món inconscient, que sabem que colonitza bona part del nostre fer racional, i tenim estratègies per fer-lo emergir i eines per poder-lo gestionar (món simbòlic, rituals, genograma, moviments sistèmics...).

Aquest tractament del món emocional profund, carregat de narratives dels infants i llurs famílies a les quals podem donar sentit, ens permet acompanyar-los d'una manera subtil i afinada que els dóna el reconeixement i la seguretat necesssaris per estar més disponibles per als aprenentatges.

El segon aspecte, amb el qual maturaré en el desenvolupament d'aquesta pregunta tan àmplia, es basa en quatre eixos que d'alguna manera nosaltres insistim que formin part permanent en el desplegament dels diferents àmbits del currículum, no com una proposta didàctica més, sinó com una oportunitat per donar sentit a un dels grans objectius que al meu entendre hauria de potenciar l'escola: que tots els infants i joves surtin dels centres educatius havent construit una veritable narrativa de la seva vida i del sentit que aquesta comporta en el marc de l'espècie i del territori terra que habitem.

Aquests quatre eixos són les arrels (d’on venim), la identitat (qui som), els vincles (amb qui ens relacionem, com ens relacionem) i el fet de donar ales per volar (cap on anem). Són les quatre 
grans preguntes que la humanitat s'ha fet des de les albors dels temps, i resulten vitals per conèixer-nos individualment i per desenvolupar-nos com a persones que compartim un mateix llinatge i territori global, que hem de preservar.

La relació família-escola és fonamental des de l'enfocament sistèmic, ens en pots fer cinc cèntims?

La pedagogia sistèmica treballa des de tres àmbits específics, ben definits i suficientment desenvolupats: la relació amb les famílies; el treball en els equips educatius, o en qualsevol equip professional, i la intervenció educativa amb els nens $\mathrm{i}$ joves atenent a les seves diferents etapes evolutives i aplicant algunes de les aportacions més recents en l'àmbit de l'educació, tant des de la neurobiologia, com des de les intel-ligències múltiples, etc.

Encara que de la importància de la relació família-escola se'n parla des de fa temps, em temo que la realitat és que en el sistema educatiu, encara, no hem trobat la fórmula adequada per encarar-la d'una forma eficaç, ja que en certa manera segueix prevalent la sensació que les famílies poden ser un risc potencial si s'impliquen en els assumptes dels docents. En aquest sentit, la pedagogia sistèmica introdueix algunes novetats importants, i voldria destacar-ne dues.

D’una banda, confereix a la família la prioritat que té respecte a l'educació dels fills. Sense cap dubte, els pares són els primers, i últims, responsables d'aquesta educació, i, per tant, cal donar-los un lloc prioritari, entre altres coses perquè si no hi hagués pares i mares no hi hauria fills, i sense nens i nenes no hi ha escoles. Per tant, moltes gràcies, papes i mames, per portar els vostres fills/es a les nostres escoles!

D'altra banda, hem pogut comprovar, una vegada i una altra, que sense l'aprovació dels pares, especialment, i fins i tot de la mestra i de la mateixa escola, els infants no tenen èxit escolar. En aquests casos, quan van al centre educatiu senten que no tenen el permís dels pares per aprofitar tot el que aquest els ofereix si aquests no miren amb bons ulls l'escola, o, si més no, alguns aspectes substancials de l'escola. Això ens porta a considerar de primer ordre l'establiment de ponts de comunicació i confiança entre l'escola i les famílies.
Sense intenció de generalitzar, perquè cada cas és un món, pots donar algun consell per tal de generar actituds en els docents que afavoreixin una bona comunicació entre l'escola i la família? $\mathrm{Al}$ fet de considerar que els pares són primers, que no vol dir que quan entren a l'escola poden decidir què s'hi fa, ja que això és competència dels professionals, i de donar-los les gràcies per portar els seus fills als centres, cal sumar-hi el fet que els pares i mares sempre ho fan el millor que saben, i poden, en cada moment respecte a l'acompanyament dels seus fills i filles. Aquest és un aspecte polèmic en alguns casos, perquè els educadors/ores poden detectar famílies que sembla que no compleixen aquest requisit, tot $\mathrm{i}$ que al darrere segurament hi ha un sentit complex que produeix que l'acompanyament no sigui funcional. Cal aprendre a copsar aquests sentits per poder fer intervencions més ajustades i més favorables a la comunicació i la inclusió.

Hi hauria un quart aspecte important per generar aquestes actituds afavoridores de la comunicació amb les famílies, i es basa en el fet que l'escola ha de ser transparent per als pares, que han de saber què s'hi fa, com es fa, i per què es fa d'una manera determinada. Les escoles han de fer pedagogia amb les famílies, no escola de pares.

Aquests quatre aspectes faciliten la base necessària per a qualsevol procés de comunicació exitós: la confiança, que és una actitud general que té repercussions favorables en molts àmbits. Confiança, reconeixement i respecte subtil per les diferents maneres de fer i de ser i pel propi destí de cada persona, tant dels alumnes com de llurs pares i mares. Estem parlant, segurament, d'una manera de fer per part dels professionals que requereix una formació personal important.

Actualment, saps si hi ha gaires centres o equips docents que enfoquin el model educatiu des de la mirada sistèmica?

Es fa difícil parlar de centres sistèmics; de fet, no sé si tindria gaire sentit que n'hi hagués. Potser podem parlar de centres que tenen en el seu projecte educatiu definicions i pràctiques que estan plantejades des de la perspectiva sistèmica, que s'han apropat a aquesta mirada i que procuren desplegar-la no solament en el contingut i l'apli- 
cació del currículum sinó també en totes les esferes de la vida de la comunitat educativa.

Si plantegem la pregunta des d'aquesta tessitura, podem dir que hi ha moltes escoles que en l'actualitat estan en aquest procés, cadascuna amb ritmes, intensitats i resultats diversos. Des de la Xarxa de Pedagogia Sistèmica que, juntament amb un equip de col-laboradors/ores molt ampli, vam crear amb Mercè Traveset (que malauradament ens ha deixat recentment), i que és un dels seus grans llegats compartits, tenim un dels àmbits concretat en un grup d'escoles que ens trobem un cop al mes a l'ICE de la UAB, institució que des dels inicis d'aquest moviment l'ha acollit i potenciat.

A aquestes trobades hi assisteixen els equips directius dels centres, que estan formats per professionals que han fet la formació de llarga durada en pedagogia sistèmica, a l'Institut Gestalt o en alguna de les universitats catalanes que en l'actualitat n'ofereixen (UAB, URV, UdG), amb la clara voluntat de potenciar en els seus centres la mirada de la pedagogia sistèmica. Cada curs escolar es tracten temes concrets i diversos, tan amplis i suggerents com les dinàmiques d'inclusió, acollida i acomiadament; la gestió del lideratge distributiu; la manera de millorar la relació amb les famílies; els models de desenvolupa- ment curricular des de la perspectiva sistèmica... Aquestes trobades es fan des de fa deu anys i en el grup hi participen una trentena d'escoles i una cinquantena de professionals.

Com a expert que assessora equips docents de diversos centres de Catalunya deus tenir una visió sobre com es podria millorar la formació dels mestres; a parer teu, què creus que s'hauria d'incloure en la seva formació inicial?

Abans que per aquelles coses del directe se moblidi, hi ha un element que caldria contemplar en la formació inicial dels mestres que és ineludible i que em temo encara estem lluny d'incloure: la dimensió personal. Sense un bon coneixement d'un mateix/a, sense el reconeixement de les nostres servituds emocionals inconscients, sense una modulació de les nostres actituds arrelades en dinàmiques poc funcionals per a la salut i per al benestar de les relacions, és poc probable que la intervenció dels educadors/ores permeti desplegar molts dels aspectes rellevants que hem anat desgranant arran d'aquesta conversa. Aquesta formació personal ens portaria a una millora de les actituds bàsiques per crear contextos escolars d'alt contingut vital i ens ajudaria a aprendre a mirar amb bons ulls, que seria una fita fantàstica en aquesta direcció.

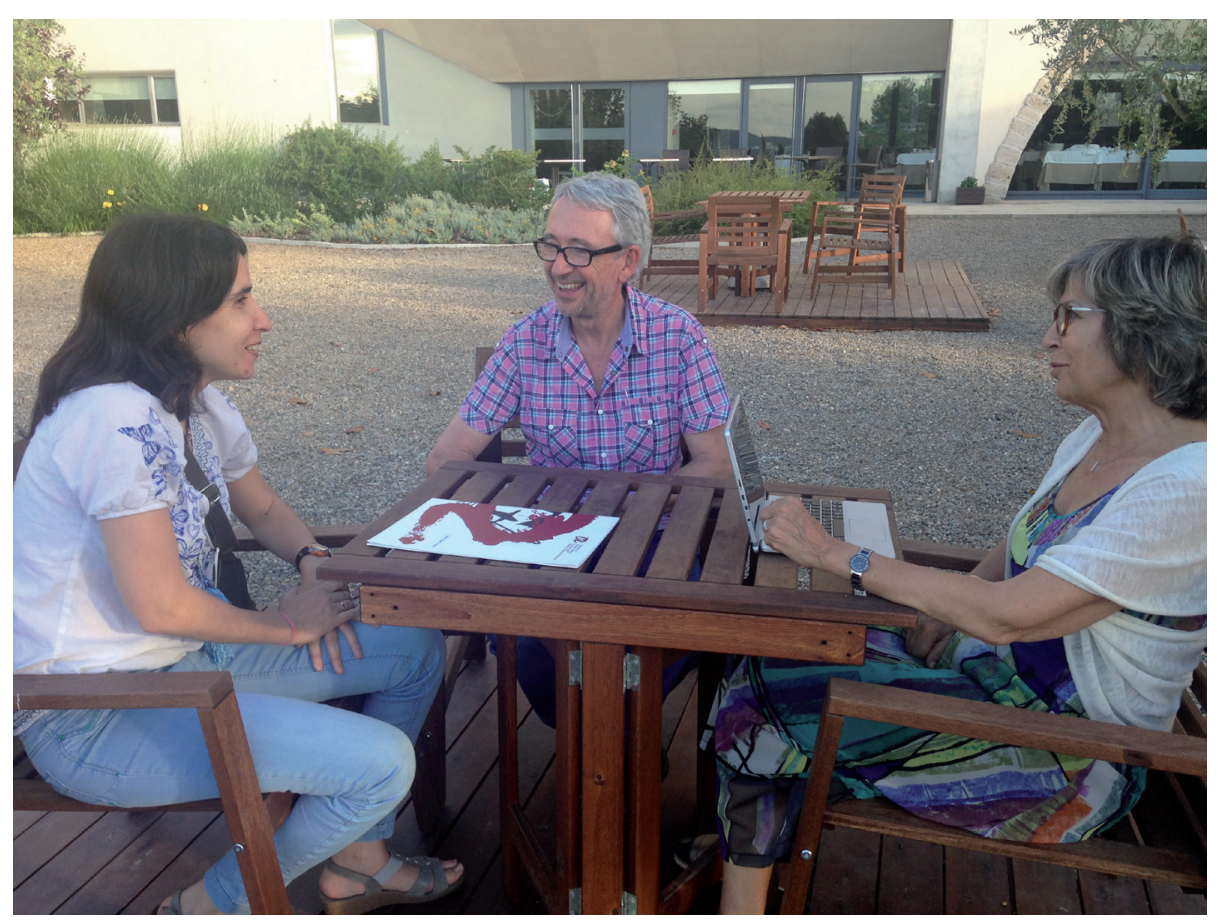


Salvat aquest primer aspecte, diria que n'hi ha un altre d'important a considerar: fomentar les bases d'una bona educació emocional sistèmica. $\mathrm{Fa}$ anys que es parla de la necessitat d'incorporar la dimensió emocional, i això encara no s'ha aconseguit d'una forma explícita. Amb el que ara sabem, no solament es tracta de fer una tasca emocional cognitiva, sinó molt més centrada en el món inconscient. Aquest aspecte aniria complementat per una major consideració de la dimensió corporal conscient en els escenaris educatius, així com dels valors que es desprenen de les visualitzacions i la meditació.

Caldria incloure, també, un major coneixement sobre les dinàmiques relacionals per afavorir un tema que es toca desquitllada en les formacions inicials com és la relació amb les famílies, que s'hauria d'ampliar amb la gestió de les relacions en el marc dels equips professionals, $i$, sens dubte, en el marc de les aules, per una banda, i en el de la comunitat educativa i l'administració, per una altra. El lideratge és bàsic per transformar el sistema educatiu actual.

Podria estendre'm fins a l'infinit en aquesta pregunta, i, per descomptat, podria abastar àmbits de tipus més metodològic pel que fa a la intervenció educativa amb els infants i en el desplegament del currículum, però maturaré en un darrer aspecte, que té a veure amb el món simbòlic. El futur de l'educació rau en bona mesura en aquest àmbit, per això em sembla de vital importància que se li doni un lloc rellevant dins de la formació inicial dels futurs educadors/ores.

Què vull dir amb el món simbòlic? Doncs diverses coses a la vegada. Una d’elles és el que fa referència als rituals. Els professionals de l'acompanyament haurien de contemplar, i gestionar, rituals d'acollida, de seguiment, de procés, i d'acomiadament, que, junts, garanteixin aspectes bàsics del pas d'infants i adults pels centres educatius.

Una altra és tot el que fa referència a la creació de relats, és a dir, tenir la capacitat de llegir l'expressió vital dels infants i joves per tal d'ajudar-los a construir relats més afavoridors que els permetin transmutar possibles limitacions, frustracions i drames que els tenen bloquejats en el seu procés de vida i que els impedeixen aprendre d'una forma satisfactòria o els limiten en els seus processos de creixement.

Ens calen mestres amb capacitat creativa, compassiva i generosa, que mirin els seus alumnes i llurs famílies amb el que sí que tenen i no amb el que els falta, que es projectin en les solucions i no en els problemes, en definitiva, que actuïn des de la responsabilitat del seu registre adult, potenciant els talents i els somnis dels infants i joves que acompanyen. Adults que siguin capaços de moure's des de la dimensió del cor, i no solament des de l'àmbit cognitiu.

\section{Per acabar, vols afegir alguna reflexió?}

Una sola cosa, vital per a aquest plantejament: repetir una vegada més que ens cal aprendre a mirar-nos amb bons ulls, i això vol dir sentir que tenim permís per desplegar les nostres millors capacitats $i$, alhora, que podem confiar en la vida d'una forma incondicional. Si aconseguim això, la pau romandrà en el cor de les persones i s'instaurarà definitivament en un món convuls que necessita donar un tomb per a la seva pròpia subsistència i per a la realització plena dels éssers que l'habitem.

Gràcies, Carles, per aquestes aportacions tan interessants que de ben segur ens faran reflexionar.

Gràcies a vosaltres per donar-me aquesta oportunitat de poder mostrar alguns dels aspectes més rellevants d'aquesta perspectiva educativa que tinc la impressió que aporta, especialment, una oportunitat de transformació per al sistema educatiu i per a la formació del professorat del nostre país, a banda dels altres àmbits en què pot tenir una incidència rellevant. 